\title{
Distribution and Diversity of Sand Fly Species (Diptera: Psychodidae, Phlebotominae) in Two Geoclimatic Zones of Chad
}

Israel DEMBA KODINDO ( $\square$ iskodindo@yahoo.fr)

National malaria Control Program

Demba Kodindo Israël

Ministry of Public Health, N'Djaména

Cheick Amadou Coulibaly

Universite de Mali: Universite de Bamako

Ibrahim Moussa Sissoko

University of Bamako: Universite de Bamako

\section{Bourama Traoré}

University of Bamako: Universite de Bamako

\section{André B. B. Wilke}

University of Miami Department of Public Health Sciences

John C Beier

University of Miami Department of Public Health Sciences

\section{Gunter C Muller}

The Hebrew University of Jerusalem

\section{Seydou Doumbia}

University of Mali: Universite de Bamako

\section{Short report}

Keywords: leishmaniasis, sandflies, diversity, geoclimatic zones, Chad

Posted Date: August 19th, 2021

DOI: https://doi.org/10.21203/rs.3.rs-783406/v1

License: (c) (i) This work is licensed under a Creative Commons Attribution 4.0 International License. Read Full License 


\section{Abstract}

Introduction: Leishmaniasis transmitted by sandflies is an important vector-borne disease. In Chad, information on sandflies is outdated, and so this study was designed to update the sandfly fauna.

Methods: Sandflies were collected in five health districts representing two geoclimatic zones using sticky traps and pyrethrum sprays in indoor and peridomestic habitats between September 2019 and December 2020. All collected sandfly specimens were identified based on species-level morphological characters.

Results: A total of 2,015 specimens belonging to 13 species of sandflies (one Phlebotomus and twelve Sergentomyia) were collected and identified. The vector of human cutaneous leishmaniasis, Phlebotomus duboscqi, represents $0.65 \%$ of all collected sandflies and is the only representative of the Phlebotomus genus to be collected predominantly inside human dwellings. Phlebotomus orientalis, the vector of visceral leishmaniasis previously collected in Chad in 1976 was not found in this study. Sergentomyia clydei, Sergentomyia schwetzi, Sergentomyia antennata and Sergentomyia africana were the most abundant species collected with $44.71 \% ; 22.73 \% ; 16.03 \%$ and $11.17 \%$, respectively.

Sergentomyia schwetzi and Sergentomyia dubia, the two species involved in the transmission of canine leishmaniasis, were found in five and four study sites respectively.

Conclusion: According to our results, the sandfly fauna of the two geoclimatic zones of Chad is comprised of 13 species. Our data showed that, unlike $P$. orientalis which was not found, $P$. duboscqi is present in four of the five sites surveyed. Therefore, these areas are at risk and remain potential foci of cutaneous leishmaniasis. However, the need for further studies such as vector species detection, their seasonal fluctuations and their vector competence.

\section{Background}

Leishmaniasis is a neglected tropical vector-borne disease that is preventable and treatable. It takes second place after malaria in terms of the number of people affected [1]. Worldwide, 350 million people are at risk of leishmaniasis in 88 countries.

Sandflies are the only known natural vectors of leishmaniases [2, 3]. In addition to leishmaniasis, sandflies transmit numerous viruses and pathogenic bacteria to humans and animals [4-6]. Of approximately 900 described species of sandflies, 98 transmit at least 20 different species Leishmania [3, 7].

In Chad, leishmaniasis was not considered a serious public health problem [8]. However, leishmaniasis is currently reappearing in previously non-endemic areas. Between 1966 and 1976, 64 patients were diagnosed with visceral leishmaniasis at the hospital in N'Djaména [9] and it was not until 2004 that another patient returning from Chad was diagnosed in Marseille/France [10]. For the mucocutaneous leishmaniasis (MCL) form, 6 patients were diagnosed between 1969 and 1971 [11] and another in 1978 [12]. As for cutaneous leishmaniasis (CL), 1,121 cases were reported between 1968 and 1976 [8]. 
Furthermore, a patient from Chad was diagnosed in Bangui in 2007 [13]. In 2007, during an outbreak in Sudanese refugee camp in Treguine (Chad), 200 patients tested positive for CL [14]. Also, in Amtiman, 580 cases were reported in 2015 during a retrospective study [15].

Only a few recent studies are available on the distribution and diversity of phlebotomine species vectors of leishmaniasis in Chad, and there is a lack of studies on the parasites responsible for causing CL and visceral leishmaniasis (VL) as well as what are the natural reservoirs and transmission mechanisms. Taking that into account, the present study was undertaken to update the distribution and diversity of sandfly species in five health districts located in two geoclimatic zones of Chad.

The first notes mentioning sandflies in Chad date from the colonial period. In his memoir "Ma pratique médicale au Tchad" (My medical practice in Chad), Malval spoke of papataci fever transmitted by sandflies in Abéché [16], but the first work on the inventory of sandflies identified 15 species, including two anthropophilic species [17]. Thus, Phlebotomus duboscqi and Phlebotomus orientalis were suspected to be vectors of $\mathrm{CL}$ and $\mathrm{VL}$ respectively [8].

\section{Methods}

\section{Study area}

This study was conducted in Chad, a landlocked country in central Africa with a continental climate. The country is divided into three geoclimatic zones: desert in the north, Sahelian in the center, and Sudanese in the south. Our study area covers five health districts representing two different geoclimatic zones (Sahelian and Sudanian) selected according to the epidemiological history of leishmaniasis and recent records of sandfly presence.

- Amtiman $\left(11^{\circ} 02^{\prime} 24^{\prime \prime} \mathrm{N}, 20^{\circ} 17^{\prime} 01^{\prime \prime} \mathrm{E}\right)$ is the capital of Salamat Province located in Sudanian zone in the southeast part of the country on the border with the Central African Republic. The climate is Sudanian with a rainy season from May to October and an average annual temperature of $26^{\circ} \mathrm{C}$ which can reach $40^{\circ} \mathrm{C}$ in April. Rainfall can reach $900 \mathrm{~mm}$ in certain seasons. The town of Amtiman is built on the banks of the Azoum River, which overflows every rainy season, isolating the town and causing promiscuity between the inhabitants and the domestic animals, which include large and small cattle. The vegetation is made up of trees and thorny shrubs that mostly lose their leaves in the dry season. Epidemiologically, several cases of cutaneous leishmaniasis have been reported in the province [15], however, no information on vectors is available;

- N'Djaména ( $12^{\circ} 17$ 'north, $1^{\circ} 3^{\prime}$ east) is the capital of Chad and the country's largest city. Located in the Sahelian zone, it is built on both sides of the Chari River and covers an area of $499 \mathrm{~km} 2$ with 1,653,977 inhabitants. The average annual rainfall is between 500 and $600 \mathrm{~mm}$ per year and lasts 3 to 4 months. The average annual temperature is above $30^{\circ} \mathrm{C}$, with a maximum of $47^{\circ} \mathrm{C}$ in April. This site was chosen based on historical knowledge of human leishmaniasis (visceral and cutaneous) and canine leishmaniasis [8, 9]; 
- Laï (N 9 ${ }^{\circ} 4^{\prime \prime}$ E $\left.16^{\circ} 18^{\prime}\right)$, the capital of Tandjilé Province is located in the Sudanian zone of the country. It is built on a flood plain with sandy-clay soil on the banks of the Tandjilé River, which isolates it from the country's other towns each year during most of the rainy season. Rainfall $(1,000 \mathrm{~mm})$ is spread over six months (May to October), although it is more frequent in August than in other months. The average temperature is $26^{\circ} \mathrm{C}$ and the maximum of the hottest month is $40^{\circ} \mathrm{C}$. Surrounded by large rice fields which represent the main activity of the population, other activities are fishing but also livestock concentrated on cattle, small ruminants and pigs;

- Bahili (11 $24^{\prime}$ north, $16^{\circ} 10^{\prime}$ east) located in the Loug Chari Department in the Sudanian zone, $40 \mathrm{~km}$ from Bousso, is the capital of the Chari-Baguirmi Province and is $265 \mathrm{~km}$ from N'Djaména. The average annual temperature is over $28^{\circ} \mathrm{C}$ and the annual isohyet is over $900 \mathrm{~mm}$. The main activities of the population are agriculture, livestock, trade and fishing. The main agricultural products are beans, sesame, corn and millet. The most important domestic animals are cows, sheep, goats and chickens;

- Bongor ( $\left.\mathrm{N} 12^{\circ} 16^{\prime}, 00^{\prime \prime} \mathrm{E} 15^{\circ} \mathbf{2 2}^{\prime} \mathrm{O0} \mathrm{0}^{\prime \prime}\right)$ is the capital of the Mayo Kebbi East Province. It is located in the Sudanian zone in southwestern Chad, $236 \mathrm{~km}$ from N'Djamena, and shares its international border with Cameroon. The annual isohyet is over $900 \mathrm{~mm}$ per year and the average annual temperature varies between $26^{\circ} \mathrm{C}$ and $28^{\circ} \mathrm{C}$. The city is built on the banks of the Logone River in a flood plain where rice cultivation, market gardening, fishing, and the raising of small ruminants and pigs are the main activities of the local population. The choice of this town was justified by a large number of sandflies captured during entomological studies on malaria vectors and sporadic cases of cutaneous leishmaniasis reported by the district hospital.

\section{Sand fly collection and identification}

Collections were conducted between September 2019 and December 2020 eight consecutive days per site. Two different methods were used to collect sandflies: castor oil-soaked papers and insecticide spraying. At each site, sampling was conducted in two different sandfly habitats: (i) Indoor habitats consisting of human bedrooms; and (ii) peri-domestic habitats consisting of animal shelters, and agricultural fields. At each site, 30 indoor sticky traps (IST) were set in 10 rooms for three consecutive nights and 30 outdoor sticky traps (OST) in peri-domestic habitats for three consecutive nights. For insecticide spraying, 10 rooms per site were sprayed per day for five consecutive days at a rate of 50 rooms per site. Captured sandflies were identified on the basis of morphological characters under the light microscope using dichotomous keys of Abonnenc [18].

\section{Diversity Analyses}

Biodiversity analyses were carried out for each city considering the Shannon and Dominance indices. The Shannon index takes into account species abundance and richness, less diversity will result in lower values, whereas a more diverse community composition will result in higher values. Dominance (1Simpson) index estimates the relationship between species richness and abundance, in which values close to 1 imply the community composition is comprised of a unique species and values close to 0 implies a uniform distribution between species richness and abundance [19]. Analyses were carried out 
with 10,000 randomizations where each randomization is done without replacement using a $95 \%$ confidence interval. Diversity analyses were done using Past software (v.3.16) [20].

\section{Results}

A total of 2,015 sandflies were collected and identified. The sandfly fauna included both the genus Phlebotomus (P.) and Sergentomyia (S.). Fifty-eight other specimens in the collections could not be identified due to damage during collections or the absence of essential morphological characters. These specimens were then classified as genus Sergentomyia spp. Thirteen species, comprising 2,015 specimens, were morphologically identified to the species level (Table 1). For the first time, S. dubia, $S$. schoutedeni, and $S$. fallax were collected in Chad.

Table 1

Diversity of sandfly species in the five study sites.

\begin{tabular}{|llllllll|}
\hline Genus & Species & \multicolumn{2}{l}{ Females } & \multicolumn{3}{l}{ Males } & \multicolumn{3}{c|}{ Total } \\
\cline { 2 - 8 } & & $\mathbf{n}$ & $\%$ & $\mathbf{n}$ & $\%$ & $\mathbf{N}$ & $\%$ \\
\hline Phlebotomus & P. duboscqi & 3 & 0.23 & 10 & 0.77 & 13 & 0.65 \\
\hline Sergentomyia & S. affinis vorax & 0 & 0.00 & 1 & 100.00 & 1 & 0.05 \\
\cline { 2 - 8 } & S. africana & 92 & 40.89 & 133 & 59.11 & 225 & 11.17 \\
\cline { 2 - 8 } & S. antennata & 171 & 52.94 & 152 & 47.06 & 323 & 16.03 \\
\hline S. bedfordi & 10 & 100.00 & 0 & 0.00 & 10 & 0.50 \\
\hline S. buxtoni & 4 & 44.44 & 5 & 55.56 & 9 & 0.45 \\
\hline S. clydei & 447 & 49.61 & 454 & 50.39 & 901 & 44.71 \\
\hline S. dubia & 8 & 80.00 & 2 & 20.00 & 10 & 0.50 \\
\hline S. fallax & 1 & 25.00 & 3 & 75.00 & 4 & 0.20 \\
\hline S. magna & 2 & 6.90 & 27 & 93.10 & 29 & 1.44 \\
\hline S. schoutedeni & 21 & 70.00 & 9 & 30.00 & 30 & 1.49 \\
\hline S. schwetzi & 177 & 38.65 & 281 & 61.35 & 458 & 22.73 \\
\hline S. squamipleuris & 2 & 100.00 & 0 & 0.00 & 2 & 0.10 \\
\hline Total & 938 & 46.55 & 1077 & 53.45 & 2015 & 100.00 \\
\hline
\end{tabular}

Cumulatively, males were more abundant than females for most species and collection sites except for $S$. antennata, S. bedfordi, S. dubia, S. schoutedeni and S. squamipleuris. The male-to-female sex ratio captured was approximately 1:1 (Table 1 ). 
The species richness ranged from six to 12 species among all cities surveyed. The city of N'Djamena, located in the Sahelian geoclimatic zone, had the lowest richness among all collection sites with six species. On the other hand, the city of Bongor, located in the Sudanian geoclimatic zone, yielded the highest richness comprising 12 species. However, despite yielding the lowest richness value, the city of N'Djamena had a more even community composition when compared to all other cities but Amtiman. The city of Lai yielded the highest Shannon index value as well as the lowest Dominance index value indicating a more diverse and even species composition (Table 2).

Table 2

Total number of sandflies collected in the cities of Amtiman, Bahili, Bongor, Lai, and N'Djamena, Chad.

\begin{tabular}{|c|c|c|c|c|c|}
\hline Species & Amtiman & Bahili & Bongor & Lai & N'Djamena \\
\hline P. duboscqi & 5 & 2 & 1 & 5 & 0 \\
\hline $\begin{array}{l}\text { S. affinis } \\
\text { vorax }\end{array}$ & 0 & 0 & 1 & 0 & 0 \\
\hline S. africana & 77 & 17 & 62 & 33 & 36 \\
\hline S. antennata & 30 & 41 & 193 & 29 & 30 \\
\hline S. bedfordi & 0 & 0 & 4 & 6 & 0 \\
\hline S. buxtoni & 0 & 0 & 6 & 0 & 3 \\
\hline S. clydei & 303 & 89 & 203 & 110 & 196 \\
\hline S. dubia & 1 & 0 & 7 & 1 & 1 \\
\hline S. fallax & 0 & 0 & 3 & 1 & 0 \\
\hline S. magnus & 8 & 4 & 12 & 5 & 0 \\
\hline $\begin{array}{l}\text { S. } \\
\text { schoutedeni }\end{array}$ & 1 & 6 & 6 & 17 & 0 \\
\hline S. schwetzi & 121 & 30 & 108 & 45 & 154 \\
\hline $\begin{array}{l}\text { S. } \\
\text { squamipleuris }\end{array}$ & 0 & 1 & 0 & 1 & 0 \\
\hline $\begin{array}{l}\text { Relative } \\
\text { Abundance }\end{array}$ & 546 & 190 & 606 & 253 & 420 \\
\hline $\begin{array}{l}\text { Species } \\
\text { Richness }\end{array}$ & 8 & 8 & 12 & 11 & 6 \\
\hline $\begin{array}{l}\text { Shannon } \\
\text { Index }\end{array}$ & $\begin{array}{l}1.22 \text { (IC: } \\
1.15-1.3)\end{array}$ & $\begin{array}{l}1.46 \text { (IC: } \\
1.33-1.57)\end{array}$ & $\begin{array}{l}1.57 \text { (IC: } 1.5- \\
1.64)\end{array}$ & $\begin{array}{l}1.67 \text { (IC: } \\
1.56-1.78\end{array}$ & $\begin{array}{l}1.17 \text { (IC: } \\
1.10-1.23)\end{array}$ \\
\hline $\begin{array}{l}\text { Dominance } \\
\text { Index }\end{array}$ & $\begin{array}{l}0.38 \text { (IC: } \\
0.34-0.41)\end{array}$ & $\begin{array}{l}0.30 \text { (IC: } \\
0.25-0.35)\end{array}$ & $\begin{array}{l}0.25 \text { (IC: } \\
0.24-0.27)\end{array}$ & $\begin{array}{l}0.25 \text { (IC: } \\
0.22-0.30)\end{array}$ & $\begin{array}{l}0.36 \text { (IC: } \\
0.34-0.39)\end{array}$ \\
\hline
\end{tabular}




\section{Discussion}

In Chad, data on the diversity and distribution of sandflies are dated. The first inventory of the sandfly fauna, which combined the work of Abonnec and other researchers with that of Lewis and Hitchcock, collected a total of 15 sandfly species [17].

Even though 15 species of sandflies were previously recorded in Chad, during this study only 13 species were collected. Furthermore, five sandfly species that were previously collected were not found in this study (P. orientalis, P. bergeroti, S. murphyi, S. inermis and S. adleri,). Conversely, we collected three additional species that were never reported in Chad (S. dubia, S. schoutedeni, and S. fallax). The absence of species from the previous fauna and the appearance of species detected for the first time would be due either to collection method, misidentification, environmental disturbances of human or climatic origin leading to their disappearance, and to the migration of other species that have adapted and proliferated in their new environment.

P. duboscqi, already reported in Chad (in N'Djaména, Abéché and Ouarai), is the only representative of the genus Phlebotomus identified during this study and collected in four of the five districts, which could suggest that transmission of the disease is possible throughout the area. The range of distribution of this species is very wide. It extends from Senegal to Ethiopia through the Gulf of Guinea and the neighboring countries of Chad [18, 21-23]. This species is the vector of cutaneous leishmaniasis caused by Leishmania major in West and East Africa $[24,25]$ and is thought to be responsible for the cases of cutaneous leishmaniasis recorded in Chad $[14,15]$. P. duboscqi was mostly collected inside human houses $(76.9 \%)$. The presence of this species caught inside human houses was expected as it had already been recorded in Bamako [26] and central Mali [24]. Another epidemiologically important species of the genus Phlebotomus, Phlebotomus orientalis, a vector of visceral leishmaniasis in East African countries [27], already identified in Chad, was not found during our surveys, although it has been reported in countries bordering Chad, specifically Niger, Sudan and Nigeria $[18,21,28]$. The absence of this important species in our collections despite its reported presence in neighboring countries does not prove that this species does not exist but may be due to collection methods because in the survey that allowed its collection, light traps were used [17]. In Ethiopia, light traps were more effective in capturing this species than sticky traps and pyrethrin spraying combined [29].

Species of the genus Sergentomyia were almost predominant in the collections compared to the genus Phlebotomus with $99.35 \%$ of species identified. This predominance has already been observed in many surveys, notably in Chad [17], Nigeria [23], Cameroon [22] and Senegal [30]. Four species of this group (S. clydei, S. schwetzi, S. antennata and S. africana) were the most common and abundant both in the peridomestic environment and in human habitations. They represented $95 \%$ of all Sergentomyia captured. These species have a wide distribution in the Afrotropical zone, extending from West Africa to Ethiopia, much of East Africa [18] and are most often found in large numbers [21, 31]. The identification of DNA and/or parasites of Leishmania in several species of the genus Sergentomyia raise questions regarding their potential role in the circulation of mammalian leishmaniasis in the Old World and has 
draw general interest [32]. S. schwetzi, S. dubia and S. clydei, three of these species, whose epidemiological importance has been published, were collected during our survey, Indeed, S. schwetzi and $S$. dubia collected indoor rooms and in the peridomestic environment as in our study, had been found infected by Leishmania infantum and involved in the transmission of canine leishmaniasis in MontRolland, Senegal [30].

During our collection, $S$. schwetzi was found in all five study sites while $S$. dubia was collected in four of the five sites. Thus, surveillance is necessary to avoid an epidemic and the establishment of an endemic focus of canine leishmaniasis in these areas in case of importation of the disease. In N'Djaména, since 1973, after six years of observation, the veterinary service identified Leishmania parasites in the smears of two infested dogs [8]. One of these two species would probably be at the origin of the transmission of the parasite to dogs, which represent the reservoir and potentially the main source of infection of visceral leishmaniasis due to Leishmania infantum to humans in Chad. Regarding S. clydei, it is the most common and most collected species since it represents $44.71 \%$ of Sergentomyia and is present in all five study sites. The latter is found infested by Leishmania major in Tunisia [33], it would participate perhaps next to $P$. duboscqi, in the transmission of cutaneous leishmaniasis.

In the present study, the number of species collected was much higher in the Sudanian zone than in the Sahelian zone and this should be influenced by the climatic and environmental conditions of temperature, humidity and rainfall. Indeed, sandfly species adapt to temperature and humidity ranges around $25-28^{\circ} \mathrm{C}$ and saturated humidity. These conditions are similar to those of the Sudanian zone, so that in N'Djamena, although many sandflies were captured compared to other sites, the species diversity was lower, with six species out of 13 identified. Our results are similar to those obtained in a study conducted in Mali in the same geoclimatic zones where nine sand fly species were identified in the Sahelian zone compared to 13 in the Sudanian zone [34]. Similarly, in Brazil, a study of sandfly community composition concluded that species richness, abundance and composition were significantly higher in the wet than in the dry environment [35].

\section{Conclusion}

A total of 13 sandfly species were collected in five cities across two geoclimatic zones of Chad. Our data showed that unlike $P$. orientalis which was not found, $P$. duboscqi was present in four of the five sites surveyed. Therefore, these areas are at risk and remain potential foci of cutaneous leishmaniasis. However, further studies are needed to further the knowledge of seasonal fluctuations in the population dynamics of sandfly species and their vector competence, as well as the detection of $P$. orientalis. This study will serve as a reference for leishmaniasis surveillance in Chad and will help to reduce the risk of transmission to both human and animal populations.

\section{Declarations}

\section{Acknowledgements}


The study was funded by the "Organisation de Coordination pour la lutte contre les Endémies en Afrique Centrale" (OCEAC), on the basis of a financial cooperation between CEMAC and the Ministry of Economic Cooperation and Development (BMZ) of the Federal Republic of Germany, through the KfW (German Development Bank). We thank Fogarty International Center of the National Institutes of Health $(\mathrm{NIH})$ for its support to the training through grant number D43TW008652.

\section{Authors' contributions}

DKI, CAC, GCM and SD designed the study. DKI, CAC, IMS, and BT performed the morphological speciation of sandflies. DKI wrote the draft manuscript. ABBW and JCB performed the data analyses. The paper was critically reviewed by authors DKI, AC, IMS, BT, ABBW, JCB, GCM, and SD. All authors read and approved the final manuscript.

\section{Ethics approval and consent to participate}

This work was submitted to and obtained permission from the Ministry of Public Health and the administrative and health authorities of the districts where the sandflies were collected. Informed consent was obtained from the owners of the rooms, animal pens and fields where the traps were placed.

\section{Consent for publication}

Not applicable.

\section{Competing interests}

The authors declare no competing interests

\section{Author details}

${ }^{1}$ Ministry of Public Health, N'Djaména, Chad

${ }^{2}$ Leishmaniasis Unit, International Center for Excellence in Research (ICER-Mali), Faculty of Medicine and Odonto-stomatology, University of Science, Techniques and Technologies of Bamako (USTTB), BP 1805 Bamako, Mali

${ }^{3}$ Department of Public Health Sciences, University of Miami Miller School of Medicine, Miami, Florida 33136 USA

${ }^{4}$ Department of Parasitology, Kuvin Centre for the Study of Infectious and Tropical Diseases. The Hebrew University - Hadassah-Medical School Jerusalem, Israel

\section{References}


1. World Health Organization. Control of the leishmaniasis. Report of a Meeting of the WHO Expert Committee on the Control of Leishmaniases. Technical Report Series. 2010.

2. Killick-Kendrick R. (1990). Phlebotomine vectors of the leishmaniases: a review. Med. Vet. Entomol. $1990 ; 4: 1-24$.

3. Ready PD. Biology of phlebotomine sand flies as vectors of disease agents. Annu Rev Entomol. 2013;58:22750.

4. Depaquit J, Grandadam M, Fouque F, Andry PE, Peyrefitte C. Arthropod-borne viruses transmitted by Phlebotomine sandflies in Europe: a review. Euro Surveill Bull Eur Sur Mal Transm Eur Commun Dis Bull. 2010;15(10):19507.

5. Cohnstaedt LW, Beati L, Caceres AG, Ferro C, Munstermann LE. Phylogenetics of the Phlebotomine Sand Fly Group Verrucarum (Diptera: Psychodidae: Lutzomyia). Am J Trop Med Hyg. 2011;84(6):913-22.

6. Alkan C, Bichaud L, de Lamballerie X, Alten B, Gould EA, Charrel RN. Sandfly-borne phleboviruses of Eurasia and Africa: Epidemiology, genetic diversity, geographic range, control measures. Antiviral Res. 2013;100(1):54-74.

7. Who, Global leishmaniasis update. 2006-2015: a turning point in leishmaniasis surveillance. Weekly epidemiological record. 2017; No 38, 92, 557-572.

8. Desjeux P. Information on the epidemiology and control of the leishmaniases by country or territory. World Health Organization; 1991. WHO/LEISH/91.30.

9. Sirol J, Vedy J, Barabe P, Cesari C, Berger P. Kala-Azar in the Republic of Chad. 6 year survey at the Central Hospital of N'Djamena (Fort-Lamy). Bull Soc Pathol Exot Filiales. 1976;69(3):232-7.

10. Aubry P. Leishmaniose viscérale au retour du Tchad: cas clinique. Médecine Tropicale. 2004.

11. Sirol J, Vedy J, Delpy P. Mucocutaneous leishmaniasis in Chad. Bull Soc Pathol Exot Filiales. 1971;64(6):85665.

12. Derrien JP, Dedet JP, Vedy J, Delpy P, Sirol J. Généralisation et cancérisation sous corticothérapie d'une leishmaniose cutanéo-muqueuse. A propos d'1 cas observé au Tchad. Med Trop. 1978;38:447-51.

13. Kassa-Kelembho E, Kobangue L, Huerre M, Morvan JM. Premier cas de leishmaniose cutanée d'importation à Bangui en République Centrafricaine: Efficacité du Métronidazole. Revue du Corps de sante colonial. 2003;63(6):597-600.

14. World Health Organization. Communicable disease epidemiological profile: Central African Republic and Chad. WHO/HSE/GAR/DCE. 2009;274 p.

15. Demba KI, Baïndaou G, Tchonfinet M, Ngamada F, Ndjékoundadé A, Moussa Djibrine M, Nahor NM, Kerah-Hinzoumbé C, Saada D, Doumbia S. Étude rétrospective de la leishmaniose cutanée à l'hôpital de district d'Am Timan, Tchad. Bull Société Pathol Exot. 2015;108(2):1179.

16. Tubiana MJ. Jean Malval: Ma pratique médicale au Tchad (1926-1928). J Afr. 1994;64(1):1223. 
17. Lewis DJ, Hitchcock JC. Phlebotomine sandflies of Chad. Ann Trop Med Parasitol. 1968;62(1):11721.

18. Abonnenc E. Les phlébotomes de la région éthiopienne (Diptera, Psychodidae). ORSTOM. 1972; 289 p.

19. Shannon CE. A mathematical theory of communication. Bell Syst Tech J. 1948;27:379-423.38.

20. Hammer $\emptyset$, Harper DATT, Ryan PDPAST. Paleontological Statistics Software Package for education and data analysis. Palaeontol Electron. 2001;4:9.

21. Widaa SO, Ahmed KA, Bari AAE, Ali MM, Ibrahim MA, Bashir MA, Mastour AHA, Yagi ZA, Hassan MM. Sandflies (Diptera: Psychodidae) in a focus of visceral leishmaniasis in White Nile, Sudan. Mem Inst Oswaldo Cruz. 2012;107(4):470-5.

22. Dondji B, Duhlinska DD, Same-Ekobo A. Species Composition of the Phlebotomine Sandfly Fauna (Diptera: Phlebotominae) in Mokolo Region, Northern Cameroon. Int J Trop Insect Sci. 2000;20(3):2216.

23. Asimeng EJ. The distribution of phlebotomine sandflies (Diptera: Psychodidae) in northern Nigeria. Trop Med Parasitol. 1990;41(2):193-7.

24. Anderson JM, Samake S, Jaramillo-Gutierrez G, Sissoko I, Coulibaly CA, Traoré B, Soucko C, Guindo B, Diarra D, Fay MP, Lawyer PG, Doumbia S, Valenzuela JG, Kamhawi S. Seasonality and Prevalence of Leishmania major Infection in Phlebotomus duboscqi Neveu-Lemaire from Two Neighboring Villages in Central Mali. PLoS Negl Trop Dis. 2011;5(5):e1139.

25. Beach R, Kiilu G, Hendricks L, Oster C, Leeuwenburg J. Cutaneous leishmaniasis in Kenya: transmission of Leishmania major to man by the bite of a naturally infected Phlebotomus duboscqi. Trans R Soc Trop Med Hyg. 1984;78(6):747-51.

26. Demba-Kodindo I, Cheick-Coulibaly A, Traoré B, Sissoko I, Samake S, Doumbia S. Étude de la faune phlébotomienne des zones périurbaines de Bamako (Mali), présence de Phlebotomus (Phlebotomus) duboscqi. Bull Société Pathol Exot. 2015;108(2):1302.

27. Elnaiem DEA. Ecology and control of the sand fly vectors of Leishmania donovani in East Africa, with special emphasis on Phlebotomus orientalis. J Vector Ecol. 2011;36:23-31.

28. Isa A, Umar YA, Appah J. Species Composition of Phlebotomine Sandfly (Diptera:Psychodidae) Vectors of Leishmaniasis in Katsina State, Northern Nigeria. International Journal of Scientific Engineering Research. 2017;8:11.

29. Aklilu E, Gebresilassie A, Yared S, Kindu M, Tekie H, Balkew M, Warburg A, Hailu A, Gebre-Michael T. Studies on sand fly fauna and ecological analysis of Phlebotomus orientalis in the highland and lowland foci of kala-azar in northwestern Ethiopia. PLOS ONE. 2017;12(4):e0175308.

30. Senghor MW, Niang AA, Depaquit J, Ferté H, Faye MN, Elguero E, Gaye O, Alten B, Perktas U, Cassan C, Faye B, Bañuls AL. Transmission of Leishmania infantum in the Canine Leishmaniasis Focus of Mont-Rolland, Senegal: Ecological, Parasitological and Molecular Evidence for a Possible Role of Sergentomyia Sand Flies. PLoS Negl Trop Dis. 2016;10(11):e0004940. 
31. Asimeng EJ. Preliminary Account of the Phenology of Some Nigerian Savanna Phlebotomine Sandflies (Diptera: Psychodidae). J Med Entomol. 1991;28(5):578-80.

32. Maia C, Depaquit J. Can Sergentomyia (Diptera, Psychodidae) play a role in the transmission of mammal-infecting Leishmania ? Parasite. 2016;23:55.

33. Ayari C, Ben Othman S, Chemkhi J, Tabbabi A, Fisa R, Ben Salah A, BenAbderrazak S. First detection of Leishmania major DNA in Sergentomyia (Sintonius) clydei (Sinton, 1928, Psychodidae:

Phlebotominae), from an outbreak area of cutaneous leishmaniasis in Tunisia. Infect Genet Evol. 2016;39:241-8.

34. Coulibaly CA, Sissoko I, Traore B, Diallo A, Samake S, Traore SF, Doumbia S. Diversity of Sand Flies (Diptera: Psychodidae: Phlebotominae) in Two Different Eco-Climatic and Endemic Zones of Cutaneous Leishmaniasis in Mali, West Africa. J Med Entomol. 2016;53(4):923-7.

35. Antonini Y, Fernandes GW, Barata RA. Distribution of the assemblage of phlebotomine sandflies (Diptera: Psychodidae) along an environmental gradient. Biota Neotropica. 2017; 17(2).

\section{Figures}




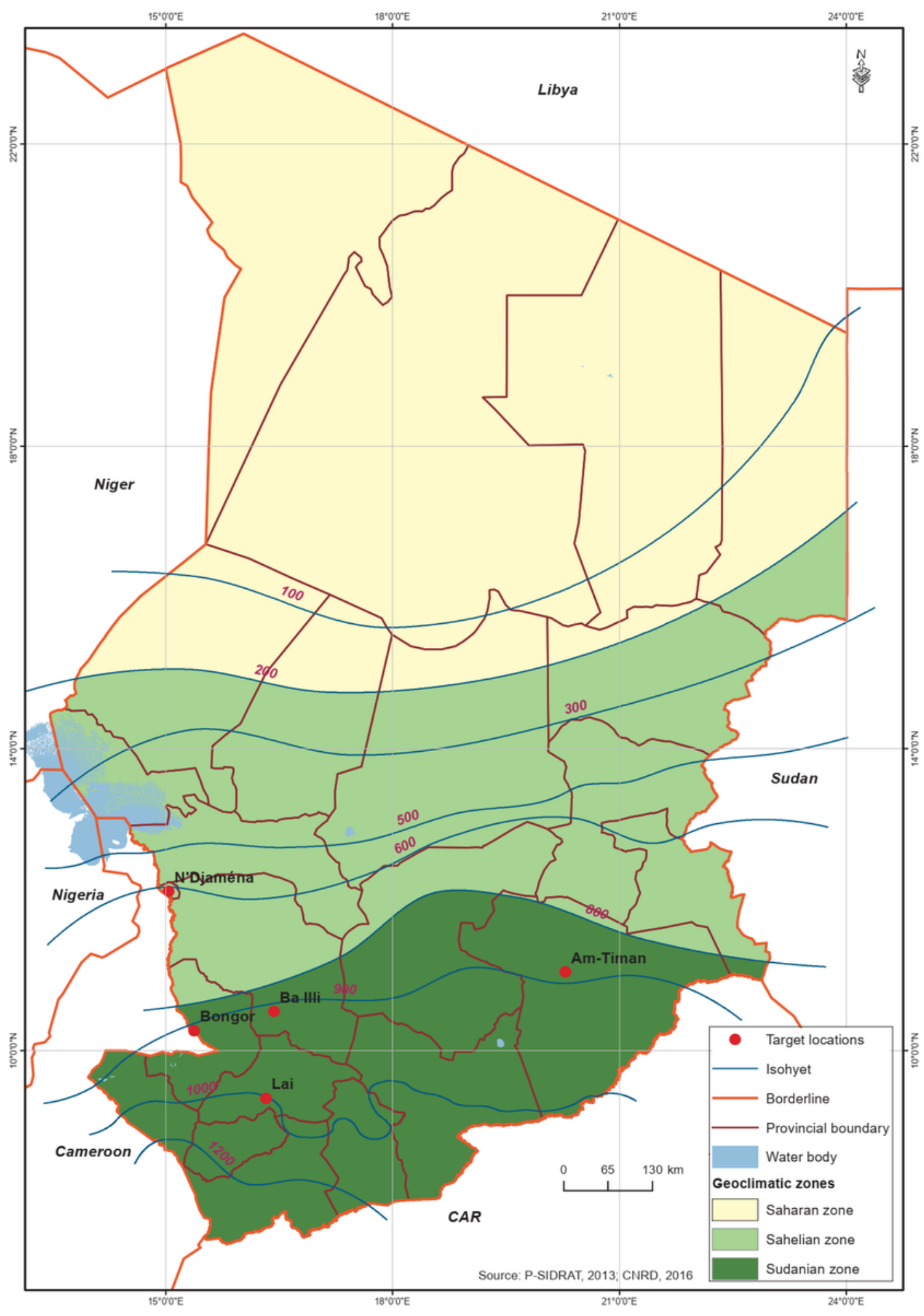

Figure 1

Map showing the geoclimatic zones and location of the five study sites

\section{Supplementary Files}

This is a list of supplementary files associated with this preprint. Click to download. 
- Abstractgraphic.docx

Page 14/14 